\section{Collagenase Cream in Non-Stitched Skin Wounds after Punch Biopsy}

Laila Deprá Tiussi ${ }^{1}$, Mayara Silva Nascimento', Felipe Lobato da Silva Costa1, Antonio Carlos de Souza Corrêa ${ }^{2}$,

Renan Kleber Costa Teixeira1, Carla Andréa Avelar Pires ${ }^{3}$, Edson Yuzur Yasojima1

\section{Abstract}

Background: The use of debriding drugs is not common in a situation of acute wound healing, despite its widespread use in chronic wound healing, with satisfactory results. Collagenase is one of the most used debriding drugs, and its application after a non-stitched skin wound biopsy could lead to a better wound healing outcome and less complication.

Methods and Findings: Fifteen Wistar rats were used in this study; four excisional wounds were performed on the dorsum of each animal. Once in a day, collagenase cream was applied in the cranial wounds, while the caudal wounds were washed with isotonic saline. After 7, 14 and 21 postoperative days, 5 animals were randomly chosen for macroscopic and microscopic wound analysis. At the $7^{\text {th }}$ postoperative day: collagenase cream induced greater monocytes invasion, fibroblast invasion, collagen deposit, angiogenesis and reepithelialization. $14^{\text {th }}$ postoperative day: collagenase cream induced greater neutrophils invasion, fibroblasts invasion, collagen deposit, reepithelialization and higher proportion of type I collagen fibers. $21^{\text {st }}$ postoperative day: collagenase cream led to greater angiogenesis and reepithelialization.

Conclusion: Collagenase cream led to a better wound healing outcome than simply saline rinse, induced earlier angiogenesis and inflammatory step; greater collagen deposit and reepithelialization.

\section{Introduction}

Skin punch biopsy is usually indicated to diagnose a disease. [1] Inflammatory skin diseases and neoplasic skin lesions, that often are hard to diagnose through the clinical aspects, are the most common reasons for the punch biopsy procedure. Moreover, the subsequent anatomopathological study is very often useful to guide the follow up of the disease $[1,2]$.
1 Experimental Surgery Laboratory. State University of Pará.Belém(PA), Brazil.

2 MorphophysiologyLaboratory. State University of Pará.Belém(PA), Brazil.

3 Dermatologydepartment. State University of Pará.Belém(PA), Brazil.

Contact information:

\section{Renan Kleber Costa Teixeira.}

Address: Mundurucus St, 2256. 66035-360Belem - PA Brasil.

Tel: (55 91)98145-1108.

”renankleberc@hotmail.com

Keywords

Wound healing;

Microbial Collagenase; Rats;

Debridement. 
The Food and Drug Administration (FDA) recommendations establish that skin biopsy should be done if there is any clinical needing, and should work as a gold standard tool to exclude or confirm neoplasic, immunologic or infectious skin lesions [3].

The medical doctor that performs skin biopsies procedure should always have in mind its benefits, but also and not less important the harms that it might cause, such as aesthetic and functional deficits $[4,5]$.

3 to $4 \mathrm{~mm}$ punches are commonly used, since that size is adequate for most of the situations, showing a good imbalance for the tissue harvesting versus the aesthetic and functional harm. However, the medical doctor should have in mind that in some situations, small skin biopsies might cause difficult to the pathologist to establish a diagnose [6-9].

Following a punch biopsy, skin wounds are commonly stitched, such technique leads to a better aesthetic and functional outcome. However, in places where the stiches are not feasible for any reason, such as technically difficult areas to perform stiches, or in patients that do not agree with that, skin wounds are usually led to heal spontaneously [10].

Skin wound that involve at rate of $1.5 \mathrm{~mm}$ per week, usually heal through the secondary intention process without complications. [11] The wound care is usually restricted to daily cleaning, antisepsis, bandage replacement and sometimes antibiotic ointment $[8,9,12]$.

The use of debriding drugs is not common in a situation of acute wound healing, despite its widespread use in chronic wound healing, with satisfactory results. Collagenase is one of the most used debriding drugs, and its application after a non-stitched skin wound biopsy could lead to a better wound healing outcome and less complication $[12,13]$.

\section{Methods}

Fifteen (8-10 weeks) male Wistar rats, weighting 250-300g were used in this study. The animals were kept in a vivarium of the Experimental Surgery Laboratory at the Para State University (LCE-UEPA) with a controlled temperature, light, humidity, and noise; water and food was provided ad libitum. The research followed the rules of Brazilian National Law for Animal Care (Law: 11.794/08). The project was previously approved by the Animal use and care committee at the Para State University (protocol 01/13).

\section{Experimental Protocol}

At day 0 , the fifteen Wistar rats were anesthetized (ketamine hydrochloride and xylazine hydrochloride $60 \mathrm{mg} / \mathrm{kg}$ and $6 \mathrm{mg} / \mathrm{kg}$, respectively, i.p.). Dorsal region was shaved using an electric shaver and then the antisepsis of region was done.

Four skin biopsies were performed on the dorsum of all animals, 2 each side of median line $(2 \mathrm{~cm}$ in distance) and being divided in cranial and caudal wounds (4 cm in distance), using a $4 \mathrm{~mm}$ metallic punch. Once in a day, collagenase cream $0.6 \mathrm{UI} / \mathrm{g}$ was applied in the cranial wounds, while the caudal wounds were washed with isotonic saline solution ( $\mathrm{NaCl} 0.9 \%)$.

Substances were applied using a sterile swab, and physical restraint was adopted. During the studied period, animals remained in individual cages and isolated for their bedding through a metallic net to avoid wound infection.

After 7, 14 and 21 postoperative days, five animals were randomly chosen for macroscopic and microscopic wound analysis.

\section{Analyzed Parameters Wound area}

After euthanasia, rats were positioned and pictures of wounds were taken to measure wound area using the software Image $\mathrm{J}^{\circledR}$. 


\section{Histological analysis}

After euthanasia, wounds were harvested, fixed in $10 \%$ formaldehyde, embedded in paraffin, and stained using Hematoxyline-Eosine (HE) and PicroSiriusred (PS). In HE stained tissues; multiple sections were analyzed with regard to the presence of neutrophils, monocytes, angiogenesis, fibroblasts, collagen deposit and keratinocytes. These assessments were evaluated by a pathologist into: absent (score 0), mild (score 1), moderate (score 2), intense (score 3 ) [14]. In PS stained tissues, proportion of type I and III collagen fibers was measured.

\section{Statistics}

Analysis of variance (ANOVA), followed by Tukey post-hoc test correction, was performed for the area analysis and proportion of collagen fibers. KruskalWallis test was used for the histological parameters. Statistical significance was assumed at $p<0.05$.

\section{Results}

\section{Wound area}

There was no difference regarding the wound area in the analyzed periods. All skin wounds were healed on the $21^{\text {st }}$ postoperative day

\section{Histological analysis Hematoxyline-Eosine} The results in table 1, 2 and $\mathbf{3}$.

\section{Histological analisys PicrosiriusRed staining}

The results in Table 4.

There was no difference regarding the proportion of type I and type III collagen fibers on the other analyzed periods. (Figure 1)

Table 1. Histological findings inHematoxyline-Eosin staining on the $7^{\text {th }}$ postoperative day.

\begin{tabular}{|c|c|c|c|c|c|c|}
\hline & Neutrophil & $\begin{array}{c}\text { Monocyte } \\
*\end{array}$ & $\underset{*}{\operatorname{Angiogenesis}}$ & $\begin{array}{l}\text { Fibroblasts } \\
\qquad *\end{array}$ & $\underset{*}{\text { Collagen }}$ & $\underset{*}{\underset{*}{\text { Reepithelialization }}}$ \\
\hline Collagenase & $1.8 \pm 0.421$ & $2.6 \pm 0.516$ & $2.8 \pm 0.421$ & $1.9 \pm 0.316$ & $1.9 \pm 0.316$ & $1.4 \pm 0.516$ \\
\hline Saline & $1,4 \pm 0.516$ & $1.8 \pm 0.421$ & $1.6 \pm 0.699$ & $1 \pm 0.666$ & $1 \pm 0.666$ & $0 \pm 0.00$ \\
\hline
\end{tabular}

Table 2. Histological findings in Hematoxyline-Eosin staining on the $14^{\text {th }}$ postoperative day.

\begin{tabular}{|l|c|c|c|c|c|c|} 
& Neutrophil & $\begin{array}{c}\text { Monocyte } \\
*\end{array}$ & $\begin{array}{c}\text { Angiogenesis } \\
*\end{array}$ & $\begin{array}{c}\text { Fibroblasts } \\
*\end{array}$ & $\begin{array}{c}\text { Collagen } \\
*\end{array}$ & $\begin{array}{c}\text { Reepithelialization } \\
*\end{array}$ \\
\hline Collagenase & $0.6 \pm 0.843$ & $1.7 \pm 0.483$ & $1.4 \pm 0.516$ & $2.2 \pm 0.421$ & $2.2 \pm 0.421$ & $2.6 \pm 0.516$ \\
\hline Saline & $1.7 \pm 0.462$ & $1.8 \pm 0.353$ & $1.7 \pm 0.462$ & $1.5 \pm 0.534$ & $1.5 \pm 0.534$ & $0.125 \pm 0.333$ \\
\hline & \multicolumn{5}{|c}{$* 0,05$. Kruskal Wallis test. Mean and standard deviation }
\end{tabular}

Table 3. Histological findings in Hematoxyline-Eosin staining on the $21^{\text {st }}$ postoperative day.

\begin{tabular}{l|c|c|c|c|c|c|} 
& Neutrophil & $\begin{array}{c}\text { Monocyte } \\
*\end{array}$ & $\begin{array}{c}\text { Angiogenesis } \\
*\end{array}$ & $\begin{array}{c}\text { Fibroblasts } \\
*\end{array}$ & $\begin{array}{c}\text { Collagen } \\
*\end{array}$ & $\begin{array}{c}\text { Reepithelialization } \\
*\end{array}$ \\
\hline Collagenase & $0 \pm 0.000$ & $1.2 \pm 0.421$ & $1 \pm 0.000$ & $2.9 \pm 0.316$ & $2.9 \pm 0.316$ & $3 \pm 0.0$ \\
Saline & $0.4 \pm 0.516$ & $1.4 \pm 0.516$ & $2.6 \pm 0.516$ & $2.4 \pm 0.516$ & $2.4 \pm 0.516$ & $1.8 \pm 0.4$ \\
\hline & \multicolumn{7}{|c|}{$* 0,05$. Kruskal Wallis test. Mean and standard deviation } \\
\hline
\end{tabular}


Table 4. Type I and type III collagen fibers on the 14th postoperative day.

\begin{tabular}{|c|c|c|}
\hline Collagen & $\begin{array}{c}\text { Collagenase } \\
*\end{array}$ & $\begin{array}{c}\text { Saline } \\
*\end{array}$ \\
\hline Type I fiber & $64.333 \pm 11.079$ & $36.2 \pm 18.972$ \\
\hline Type III fiber & $34.666 \pm 11.079$ & $62.8 \pm 18.972$ \\
\hline & & $* 0,05$ (ANOVA) \\
\hline
\end{tabular}

Figure 1: Wound treated with collagenase cream. Figure shows deposit of collagen fibers type I and type III on the $14^{\text {th }}$ postoperative day. Red: Type I fibers. Green/blue: type III fiber.

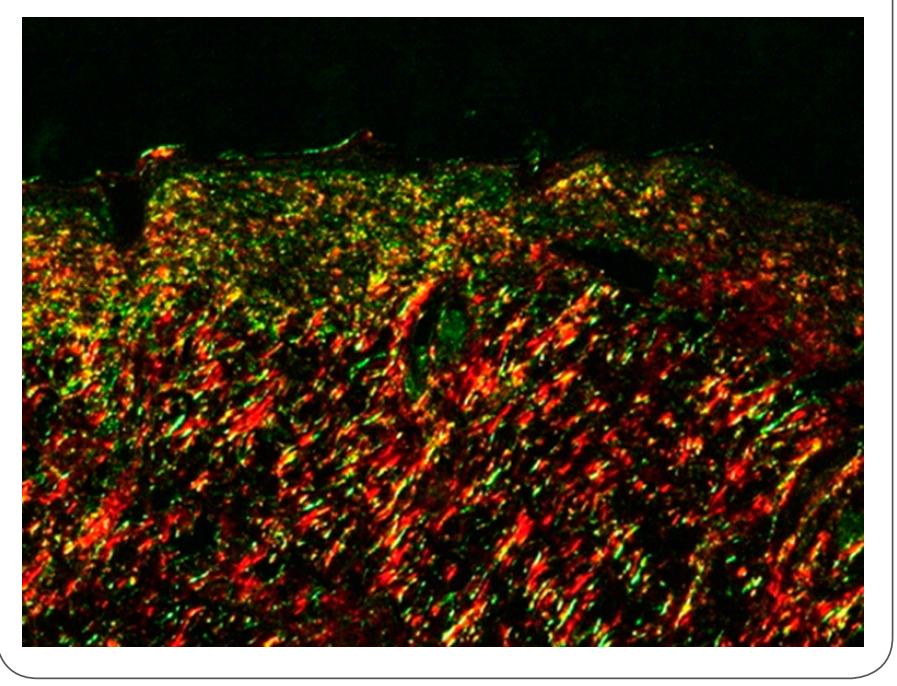

\section{Discussion}

Wound contraction is the main mechanism of wound closure in rodents [15]. Contraction occurs when miofibroblastos connect to the type I collagen fibers, generating a concentric force that ultimately leads to wound closure [16]. No difference in wound closure was noted when collagenase cream or saline was used. This fact demonstrates that there was no impairment of fibroblastic function.

Skin wounds that were treated with collagenase cream had less neutrophil invasion on the $14^{\text {th }}$ and $21^{\text {st }}$ postoperative days. Since the neutrophils are the main responsible for the wound debridement, it is reasonable to infer that the debriding effect of collagenase cream diminished the requirement of neutrophils. This fact can result in less oxidative burst and local inflammatory reaction [17].

Collagenase cream induced to greater monocytes invasion at the $7^{\text {th }}$ postoperative day. However, on the subsequent analyzed periods monocytes invasion was similar. Monocytes are the responsible for the sequel of healing process; they attract fibroblasts and stimulate the angiogenesis [17]. Greater presence of monocytes after 7 days, elicit that collagenase cream induced to a more rapid wound healing sequence.

The angiogenesis is a crucial step, since the newly formed vessels promote the washout of toxins and the income of necessary nutrients for the tissue repair [10]. Collagenase cream induced to an intense angiogenesis on the $7^{\text {th }}$ postoperative day. This fact strengthens that those wounds had a quicker wound healing process. Saline also showed intense angiogenesis, however, this was observed only at the $21^{\text {st }}$ postoperative day.

Fibroblastic cells are the main responsible for the formation of the consolidated scar and are directly related to the collagen deposition [18]. In this setting, collagenase cream induced to greater fibroblastic cell invasion at the $7^{\text {th }}$ and $14^{\text {th }}$ postoperative days. Collagen deposition followed the same pattern observed for the fibroblastic cells. 
Such finding demonstrates that collagenase cream leads to a quicker wound healing, where the early wound is richer in collagen deposit, which may lead to more resistant wounds. On the other hand, collagenase cream does not enhance the total amount of collagen in the consolidated scar. The same amount of collagen was observed in wound treated with saline or collagenase ate the $21^{\text {st }}$ postoperative day.

Initially the wound is rich in type III collagen fibers, which is constantly being substituted for type 1 collagen fibers during the wound healing sequence. Type I fibers are thicker and more efficient to cause wound contraction [18]. Collagenase cream showed greater proportion of type I collagen fibers at the $7^{\text {th }}$ day and no difference on the other analyzed periods; however, such finding was not translated to a smaller wound area.

Reepithelialization is the final and the most important step in the wound healing process of humans [19]. Collagenase cream induced to a more intense reepithelialization in all analyzed periods. It is remarkable that at the $7^{\text {th }}$ postoperative day, no signs of reepithelialization were detected in the wound treated with saline, and that process was sorely occurring when collagenase cream was used.

Early reepithelialization is very important to the skin wound healing process. It creates a barrier between the skin and the environment, reduces the dryness of the wound and the probability of wound infection, diminishes the pain and discomfort and accelerate the wound healing.

\section{Conclusion}

Daily topical application of colagenase cream led to a better wound healing process than simply washing with saline. It induced to a shorter inflammatory step, earlier angiogenesis, collagen deposit and reepithelialization.

\section{Conflict of interest}

None.

\section{Financial source}

Amazon Foundation for Research Funding of Para State (FAPESPA).

\section{References}

1. Scope A, Halpern AC. Diagnostic procedures and devices. In: Wolff K, Goldsmith LA, Katz SI, Gilchrest BA, Paller AS, Leffell DJ, editors. Fitzpatrick's Dermatology in General Medicine. New York: McGraw-Hill; 2007. p. 42

2. Werner B. Skin biopsy and its histopathologic analysis. Why? What for? How? Part I. An Bras Dermatol. 2009; 84(4): 391-5.

3. U.S. Department of Health and Human Services Food and Drug Administration Center for Drug Evaluation and Research. Guidance for Industry Chronic Cutaneous Ulcer and Burn Wounds-Developing Products for Treatment. Jun, 2006. Available at: http://www.fda.gov/cber/gdlns/ulcburn.htm.

4. Ackerman AB, Böer A, Bennin B, Gottlieb G. Proper biopsy. In: Histologic Diagnosis of Inflammatory Skin Diseases. An Algorithmic Method Based on Pattern Analysis. Nova York: Ardor Scribendi; 2005. pp. 171-9

5. Boyd AS, Neldner KH. How to submit a specimen for cutaneous pathology analysis. Using the ' 5 D's' to get the most from biopsies. Arch Fam Med. 1997; 6: 64-6

6. Zuber TJ. Punch biopsy of the skin. Am Fam Physician. 2002; 65: 1155-8, 1161-2, 1164

7. Alguire PC, Mathes BM. Skin biopsy techniques for the internist. J Gen Intern Med. 1998; 13: 46-54

8. Todd P, Garioch JJ, Humphreys S, Seywright M, Thomson J, du Vivier AW. Evaluation of the 2-mm punch biopsy in dermatological diagnosis. ClinExpDermatol. 1996; 21: 11-13

9. Werner B. Skin biopsy and its histopathologic analysis. Why? What for? How? Part II. AnBrasDermatol. 2009; 84(5): 507-13.

10. Antonio CR, Tímpano DL, Garcia AC. Biopsy. Rev Bras Med. 2010; 67(9): 22-32.

11. Cardinal M, Eisenbud DE, Phillips T, Harding K. Early healing rates and wound area measurements are reliable predictors of later complete wound closure. Wound Repair Regen. 2008; 16 : 19-22. 
12. Mandelbaum SH, Di Santis EP, Mandelbaum MHS. Cicatrization: current concepts and auxiliary resources - Part II. An. Bras. Dermatol. 2003; 78(5): 521-2.

13. Weckroth M, Vaheri A, Lauharanta J, Sorsa T, Konttinen YT. Matrix metalloproteinases, gelatinase and collagenase, in chronic leg ulcers.J InvestDermatol. 1996; 106(5): 1119-24

14. Garros IC, Campos AC, Tambara EM, Tenorio SB, Torres OJ, Agulham MA. Extract from Passifloraedulis on the healing of open wounds in rats: morphometric and histological study. Acta Cir Bras. 2006; 21(3): 55-65.

15. Galiano RD, Michaels J 5th, Dobryansky M, Levine JP, Gurtner GC. Quantitative and reproducible murine model of excisional wound healing. Wound Repair Regen. 2004; 12(4): 485-92.

16. Berry DP, Harding KG, Stanton MR, Jasani B, Ehrlich HP. Human wound contraction: collagen organization, fibroblasts, and myofibroblasts. PlastReconstr Surg. 1998; 102(1): 124-34.

17. Koh TJ, DiPietro LA. Inflammation and wound healing: the role of the macrophage. Expert Rev Mol Med. 2011; 11: 13: e23. doi: $10.1017 /$ S1462399411001943.

18. Doillon CJ, Dunn MG, Bender E, Silver FH. Collagen fiber formation in repair tissue: development of strength and toughness. CollRelat Res. 1985; 5(6): 481-92.

19. Lawrence CM, Comaish HS, Dahl MGC. Excision of skin tumors without wound closure. Br J Dermatol 1986; 115(5): 563-71

\section{Comment on this article:}

\section{f] (B) in $8+\mathbf{S} P$}
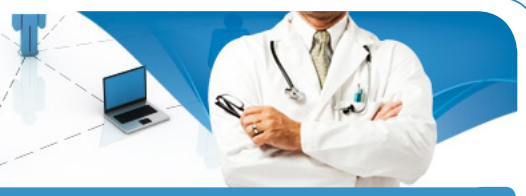

http://medicalia.org/

Where Doctors exchange clinical experiences, review their cases and share clinical knowledge. You can also access lots of medical publications for free. Join Now!

\section{Publish with iMedPub}

http://www.imed.pub

International Archives of Medicine is an open access journal publishing articles encompassing all aspects of medical science and clinical practice. IAM is considered a megajournal with independent sections on all areas of medicine. IAM is a really international journal with authors and board members from all around the world. The journal is widely indexed and classified Q1 in category Medicine. 